\title{
Audacia, delicadeza y retórica. Giacomo Serpotta y el ciclo de las Virtudes Seráficas para la Basílica de San Francesco en Palermo
}

\author{
Juan Antonio Sánchez López \\ Universidad de Málaga \\ jasanchez@uma.es
}

RESUMEN: Giacomo Serpotta (1656-1732) es, quizás, uno de los más grandes escultores del Barroco. Pese a gozar de un palpable y creciente reconocimiento historiográfico, todavía es un perfecto desconocido en términos universales. Su actividad en un contexto italiano relativamente periférico (Sicilia) y la especialización en la técnica del estuco podrían explicar que todavía persista su consideración más como decorador que escultor. Sin embargo, sus celebradas intervenciones en los espacios sacros provocaron que la presencia del elemento escultórico jugase un papel decisivo y clave en términos de función, ornamentación, discurso y mensaje, en aras a la apetecida conversión del conjunto en un auténtico artefacto retórico, de incalculable eficacia comunicativa y persuasiva. En este artículo se analizan y reivindican críticamente tales aspectos, a la par que se estudia, desde la doble perspectiva histórico-artística y estético-iconográfica, la antológica serie de las Virtudes Seráficas acometida, hacia 1723, para la Basílica de San Francesco en Palermo.

PALABRAS CLAVE: Escultura; Barroco; Iconografía; Ornamentación; Arquitectura; Italia; Franciscanismo.

\section{Audacity, Delicacy and Rhetoric. Giacomo Serpotta and the Cycle of the Seraphic Virtues for the Basilica of San Francesco in Palermo}

ABSTRACT: Giacomo Serpotta (1656-1732) is perhaps one of the greatest sculptors of the Baroque. He is still a perfect unknown in universal terms, despite enjoying an evident and growing historiographical recognition. His activity in a relatively peripheral Italian context (Sicily) and his specialization in stucco technique may be the reason for his persistent consideration more as a decorator than as a sculptor. However, his celebrated contributions in sacred spaces led to the presence of the sculptural element playing a decisive role and becoming a key factor in terms of function, ornamentation, discourse and message, making the desired conversion of the whole into an authentic rhetorical artifact, of incalculable communicative and persuasive effectiveness. This article analyzes and critically retrieves such aspects, while studying theanthological series of the Seraphic Virtues created around 1723 for the Basilica of San Francesco in Palermo, from a double historical-artistic and aesthetic-iconographic perspective.

KEYWORDS: Sculpture; Baroque; Iconography; Ornamentation; Architecture; Italy; Franciscanism.

Contemplado desde la distancia de una perspectiva científica rigurosamente objetiva, pero también con la curiosidad de un investigador extranjero, Giacomo Serpotta (1656-1732) y su obra constituyen una paradoja barroca por y en sí misma. Su perfil profesional e histórico está ligado, de manera casi intrínseca, al imaginario cultural palermitano (Abbate, 2017). Sin embargo, la resonancia internacional del artista no es todavía equiparable a su proyección y puesta en valor entre los círculos académicos y los especialistas provenientes del mundo de la Historia del Arte, pese a las numerosas publicaciones y estudios existentes sobre su figura, personalidad y problemática escultórica. No menos relevante es el hecho de haber logrado interesar, fascinar y aun entusiasmar a un granado elenco crítico (Sessa, 2009: 51-72) y literario (Scarlini, 2017: s/p.),

Cómo citar este artículo: SÁNCHEZ LÓPEZ, Juan Antonio, «Audacia, delicadeza y retórica. Giacomo Serpotta y el ciclo de las Virtudes Seráficas para la Basílica de San Francesco en Palermo", Boletín de Arte-UMA, n. ${ }^{\circ}$ 39, Departamento de Historia del Arte, Universidad de Málaga, 2018, pp. 73-90, ISSN: 0211-8483, DOI: http://dx.doi. org/10.24310/BoLArte.2018.v0i39.5247 
cuya nómina incluye a Giulio Carlo Argan (1957: 29-33), Rudolf Wittkower (1958/1985: 456-459), Anthony Blunt (1968: 43-44), Mario Praz (1975) o Dominique Fernández (1992), entre otros. Por si todo lo referido no bastara, se referencia a Giacomo Serpotta en todas las grandes Historias del Arte universales, junto a obras emblemáticas de su producción palermitana como las sofisticadas Virtudes que modelase para el Oratorio de la Compañía del SS. Rosario de San Domenico o sus homólogas de la Basílica de San Francesco, objeto del presente trabajo.

Partimos de una realidad historiográfica evidente que nos sitúa ante una bibliografía disponible sobre Giacomo Serpotta que, a todas luces, podemos calificar de nutrida. No obstante, analizada desde una perspectiva crítica, se nos antoja algo insuficiente a la hora de descubrir y describir con exhaustividad la personalidad artística y poética del escultor, al tiempo de reflexionar y profundizar en sus facetas como escenógrafo, decorador, intérprete de las temáticas iconográficas y compositor conceptual de espacios sacros. Excepción a esta tónica son los estudios de un altamente cualificado conjunto de especialistas coordinados por Leonardo Foderà (1996), Giuseppina Favara \& Eliana Mauro (2009) y Maria Concetta Di Natale \& Maurizio Vitella (2015), junto a los relevantes trabajos de Filippo Leto (2005) y, especialmente, de Donald Garstang (1990, 2006, 2008) y Pierfrancesco Palazzotto (2013: 9-13; 2015: 81-108). Tampoco puede obviarse el histórico libro de Ernesto Basile (1911/1981) con el carismático prefacio de Corrado Ricci, en cuya primera página este último concedía al artista, que supo elevarse por encima de la comprensión estética común del tiempo y con la interpretación espontánea, segura y sabia de la naturaleza, el pomposo título de «Re dello stucco».

Por puro instinto, nuestra trayectoria heurística en el terreno de la escultura siempre nos había llevado a interesarnos por un artista de estas cualidades. La oportunidad de conocerlo, diríase en primera persona y en su contexto originario ${ }^{1}$, impulsó la idea de poder trabajar en lo sucesivo sobre su figura, una vez verificado un trabajo de campo previo que nos permitió familiarizarnos con la documentación de archivo, manuscritos, historiografía específica sobre el artista y, por supuesto, los teatros sacros que acogen su obra en la capital siciliana. De esta experiencia académica e investigadora surgió una primera aproximación historiográfica (Sánchez, 2015: 212-247) que fue el germen de un proyecto investigador ${ }^{2}$ a lo largo de 2017, en cuyo desarrollo nos proponemos avanzar en el futuro con el presente artículo y otras aportaciones.

\section{Transfigurar la arquitectura}

Salvo los inevitables matices vernáculos, el modus vivendi palermitano del XVII y el XVIII, las dos centurias comprendidas por la trayectoria de Giacomo Serpotta, no se aparta demasiado del que pudiera llevarse en otros ámbitos de Italia y fuera de ella en esta época; aunque, eso sí, con matices y cierta personalidad propia. De hecho, en el contexto siciliano de la época se constata el mismo afán por ostentar e impresionar ad oculos que percibimos en España, más por cuestiones puramente culturales que circunstancialmente políticas. En cualquier caso, esa ansia desmedida por aparentar, tan incorregiblemente barroca, se despliega en el contexto siciliano en abierta sintonía con una manifiesta e irreprimible tendencia a la expresión desbordante y comunicativa, que se vería plasmada en los repertorios festivos (Mínguez: 2014) y, por supuesto, en la configuración externa, pero sobre todo interna, de las iglesias y palacios. Unas y otros se diseminan por la trama urbana como si se tratase de fastuosos joyeles que custodian entre sus muros un tesoro no menos deslumbrante y maravilloso. El vehículo procedimental para lograr tamaña 'transfiguración' de lo que es puramente material en construcción virtualmente ilusoria pasa de nuevo por el indisimulado triunfo de la escultura, aliada con el ornamento plástico que recubre los muros en su diversidad de posibilidades técnicas, estrategias discursivas y recursos matérico-texturales (Sánchez, 2015: 217). El elemento escultórico adquiere, pues, una renovada dimensión conceptual como ente artístico con personalidad propia y, como tal, puesto en valor en toda su rotundidad plástica, estética y discursiva al establecer una relación de complicidad y tensión contenida respecto a la arquitectura con la que entabla un diálogo fluido, sirviéndole de aliada y complemento.

En este punto, pocas metáforas se antojan más consustancialmente idiosincrásicas del barroco que la fachada. De la misma manera que, en el plano moral, una atractiva «fachada» (apariencia) enmascara y oculta de cara al mundo las miserias personales (por cuanto solamente uno mismo 
es quien conoce realmente el estado real de su 'casa') la fachada opera una misión similar de cara a la galería de la feria de las vanidades humanas. En efecto, una noble fachada puede encubrir e, incluso, hacer olvidar, la pobreza o las carencias de un edificio interiormente modesto, convencional o insustancial desde el punto de vista arquitectónico. No es un requisito imprescindible, desde luego, pero para el Barroco siciliano (por extensión, para el andaluz) sí. Así las cosas, si el triunfo del fachadismo proyecta hacia la vía pública lo que uno es, significa, representa y quiere que los demás piensen, comenten y digan de él, el barroco palermitano suma un sentido acumulativo y singular de la ornamentación, aunque apostando por la versatilidad absoluta de los registros escultóricos. Sin embargo, y he aquí un factor diferencial decisivo en nuestro planteamiento, estas operaciones no tienen como objetivo tanto lo que se quiera decir y tenga que decirse a la calle y desde la calle, como a partir del despliegue de medios y efectos especiales que instan a la reflexión interior desde el interior, desde el corazón mismo del propio edificio religioso que, de esta manera, se convierte en el contenedor por excelencia de la pulsión piadosa de la población que acude a ellos y se refugia en ellos como un refugio de esperanza, frente a la desesperanza del día a día.

Al hilo del discurso conviene señalar la distinción entre modi operandi bien dispares, en función de los medios materiales empleados en la consecución del perseguido objetivo de transfigurar el edificio material en el locus espiritual, ya definidos en su día como maniera sontuosa y maniera apparente (Sánchez, 2015: 219-221). Por supuesto que, desde el punto de vista del análisis del organigrama clientelar, sendos modi responden a diferentes actitudes, circunstancias económicas y realidades sociales en cuanto a un modo binario de ver las cosas, aunque se antojan convergentes, e incluso compatibles y simultáneos, en cuanto al propósito de investir (revistiéndola) a la arquitectura de una prestancia escenográfica que conjuga sabiamente lo culto y lo popular, lo naturalista y lo ilusorio. Con todo, el deseo de monumentalidad y grandilocuencia al que las construcciones palermitanas aspiran en sus exteriores se apodera de los espacios interiores, sin que las facultades parlantes y funcionalidad del edificio en cuestión se vean afectadas o erosionadas en sus fundamentos morfológicos y conceptuales.

El empleo de lujosos y costosísimos materiales pétreos es el rasgo definidor por excelencia de la maniera sontuosa, cuyo esplendor fue posible gracias a la expansión de los establecimientos eclesiásticos y la imparable colonización del tejido urbano de Palermo protagonizado por las Órdenes Religiosas asentadas en la capital. De puertas afuera, este proceso alentó la consabida rivalidad entre ellas. Desde el fuero interno, también se manifestó tamaña sintomatología por cuanto los conventos y monasterios palermitanos entraron en flagrante competición con sus homólogos romanos y napolitanos, en una pugna soterrada por la primacía y el prestigio en el seno de las respectivas Religiones ${ }^{3}$.

La integración de la escultura y la intarsia marmórea en los espacios sacros significa la apuesta por la volumetría y un horror vacui exuberante, aunque sometido a la propia disciplina arquitectónica; por lo demás, exitosa y directa consecuencia de la riqueza geológica de la isla de Sicilia y del fusionismo y reinterpretación del tratamiento de este tipo de materiales que los agentes del barroco palermitano practicaron sobre la base de las tradiciones florentina, genovesa y lombarda (Marafon, 2010: 398). De hecho, el uso de los mármoles coloreados (Piazza, 2007) se intensificó en Palermo desde las primeras décadas del Seiscientos, más allá de su empleo habitual en los monumentos funerarios (Garstang, 1996: 80-99; Hills, 1996: 405-419), provocando incluso algunos conatos de exportación de la maniera sontuosa a otras latitudes motivados por su deslumbrante hermosura y cuasi hipnótico efecto visual. Valga como ejemplo paradigmático, la iniciativa del arzobispo hispalense Jaime de $\mathrm{Pa}$ lafox y Cardona (Chillón, 2016), quien anteriormente había sido arzobispo de Palermo entre 1677-1684, para dotar a la Capilla Real de la Catedral de Sevilla de un vistoso retablo de mármoles coloreados en el que ubicar a la Virgen de los Reyes, para el que fue seleccionado un diseño de Bernardo Simón de Pineda, solicitándose informes al respecto tanto a Giovanni Battista Contini, en Roma, como al arquitecto Angelo Italia y al ingeniero Scipione Basta, en la propia Palermo (Herrera, 2012: 49-68).

El efectismo escenográfico del estuco y su presencia hegemónica en los grandes programas decorativos de los templos sirve de carta de presentación a la maniera apparente. Giacomo Serpotta la elevaría a las más altas cotas de excelencia, al convertirlo en el objeto preferente (que no exclusivo) de su actividad artística, consagrándolo como alternativa a la maniera sontuosa. Al visibilizar y reivindicar la idoneidad escultórica del estuco, Serpotta dignificaba una 
materia prima considerada 'pobre' en términos puramente crematísticos y representativos frente al bronce y el mármol, pero que también Alessandro Vittoria, Gian Lorenzo Bernini, Ercole Ferrata, Alessandro Algardi, Filippo Carcani, Giuseppe Sanmartino o Antonio Raggi habían llegado a trabajar circunstancialmente en el contexto del barroco italiano. Sin embargo, ningún otro artista como Giacomo Serpotta fue capaz de convencer, hacer 'ver' e interiorizar al público que en el estuco no solo se reconocía la materia tradicionalmente asociada a la elaboración de cornisas, molduras y decoraciones, sino un elemento plástico 'sublime' y provisto de 'nobleza' como otros, consiguiendo su optimización en una personal síntesis de fantasía, destreza y brío. Para exaltarlo bastaba con aplicar un modus operandi que conjugase el tratamiento primario con maestría compositiva y dominio técnico, en aras de categorizarlo estéticamente con dignidad, luminosidad, delicadeza, audacia, elegancia, potencia y grandiosidad (Sánchez, 2015: 223), hasta el punto de convertir su escultura «en un ejemplo imperecedero de la alquimia del arte, donde el estuco se convierte en un medio prodigiosamente expresivo» (Boucher, 1999: 184-185).

Iglesias, capillas, templos conventuales y oratorios fueron los escenarios donde Giacomo Serpotta desplegó, desde 1678 en adelante, sus habilidades como escultor, productor de modelos, escenógrafo y aún 'coreógrafo', auxiliado por su padre Gaspare (1634-1670), su hermano Giuseppe (1653-1719), su hijo Procopio (1679-1756) y su nieto Giovanni Maria (1737-1760) que, al tiempo de familiares, resultaron ser sus más estrechos colaboradores. De los espacios sacros referidos, los oratorios fueron el campo de pruebas y el laboratorio de ideas donde fueron gestándose algunas de las grandes aventuras programáticas de la religiosidad popular palermitana (Sessa, 2003: 35-54; Palazzotto, 2004 y 2016). Concebidos a modo de aula rectangular, su planimetría sumaria y perfectamente cerrada ofrecía inmejorables aptitudes para que Serpotta afrontase cada intervención en ellos como un desafío compositivo, iconográfico y estético perfectamente singularizado, al conferirles una propuesta y un 'decoro' ad hoc que hace interactuar el discurso plástico y el mensaje del oratorio con el trasfondo metafórico, dramático y lírico, intrínseco a la dedicación del mismo a una advocación concreta. La observancia de esta premisa hizo posible que la monotonía, la reiteración o el cansancio brillen por su ausencia en el discurso de los ora- torios y cedan el testigo a la versatilidad, la improvisación y la creatividad, gracias a las cuales la estructura arquitectónica adquiere una renovada apariencia y se transfigura sin verse nunca enmascarada, lesionada o alterada por la intervención escultórica. Pero no es menos cierto que al éxito de la propuesta serpottiana contribuyó decisivamente la aplicación sistemática de un trinomio esencial del que forman parte la escultura exenta programática en la que recae la carga retórica del discurso, el relieve pictórico a macro/microescala que implementa y desarrolla argumentalmente el concetto y la escultura decorativa que complementa y arropa plásticamente a una y otro (Sánchez, 2015: 235). Dentro del segundo eje nuclear destacarán los teatrini prospettici (Argan, 1957: 30), auténticas cajas escénicas al servicio de la persuasión y la composición de lugar, inteligentemente diseñados para la contemplación expresa de los misterios sacros que quedan inmersos y 'atrapados' en ellos.

Una visión compulsiva e irreflexiva de los oratorios palermitanos podría infundir la errónea e ingenua comparación con la capilla sacramental, el camarín y otros invariantes castizos emblemáticos del barroco andaluz. En principio, estas manifestaciones arquitectónicas no solo suponen la definitiva concreción del barroco (González, 2016), sino la culminación de un proceso creativo (Recio, 2001: 791-807) iniciado con el surgimiento y expansión del ornamento (Morales, 2010), a tenor del sustrato antropológico que informa las creaciones arquitectónicas en uno y otro sentido (Sánchez, 2015: 234). Deberá tenerse en cuenta, asimismo, una común y poliédrica búsqueda de la «obra de arte total» (Gesamtkunstwerk), ante el avance creciente de un desarrollo litúrgico de exacerbada sensualidad y acusado intimismo, palpable ya desde finales del XVII y consumado en el primer tercio del XVIII en el ámbito del tardobarroco internacional (Sessa, 2009: 62). Visto desde esta perspectiva podría pensarse en una conexión; pero no nos llevemos a engaño. Como hipótesis de trabajo sobre el particular proponemos la diferencia entre «transfigurar la arquitectura» (lo que persigue realmente Giacomo Serpotta) y «transmutar la arquitectura» (lo que termina sucediendo, a nuestro entender, en el territorio andaluz). El propio significado de ambos verbos proporciona el argumento de partida de nuestro razonamiento, por cuanto transfigurar es «hacer cambiar de figura (aspecto) a una persona o cosa»; en nuestro caso, una construcción que sigue siendo 'reconocible' en su esencialidad volumétrica, espacial y perimetral como 


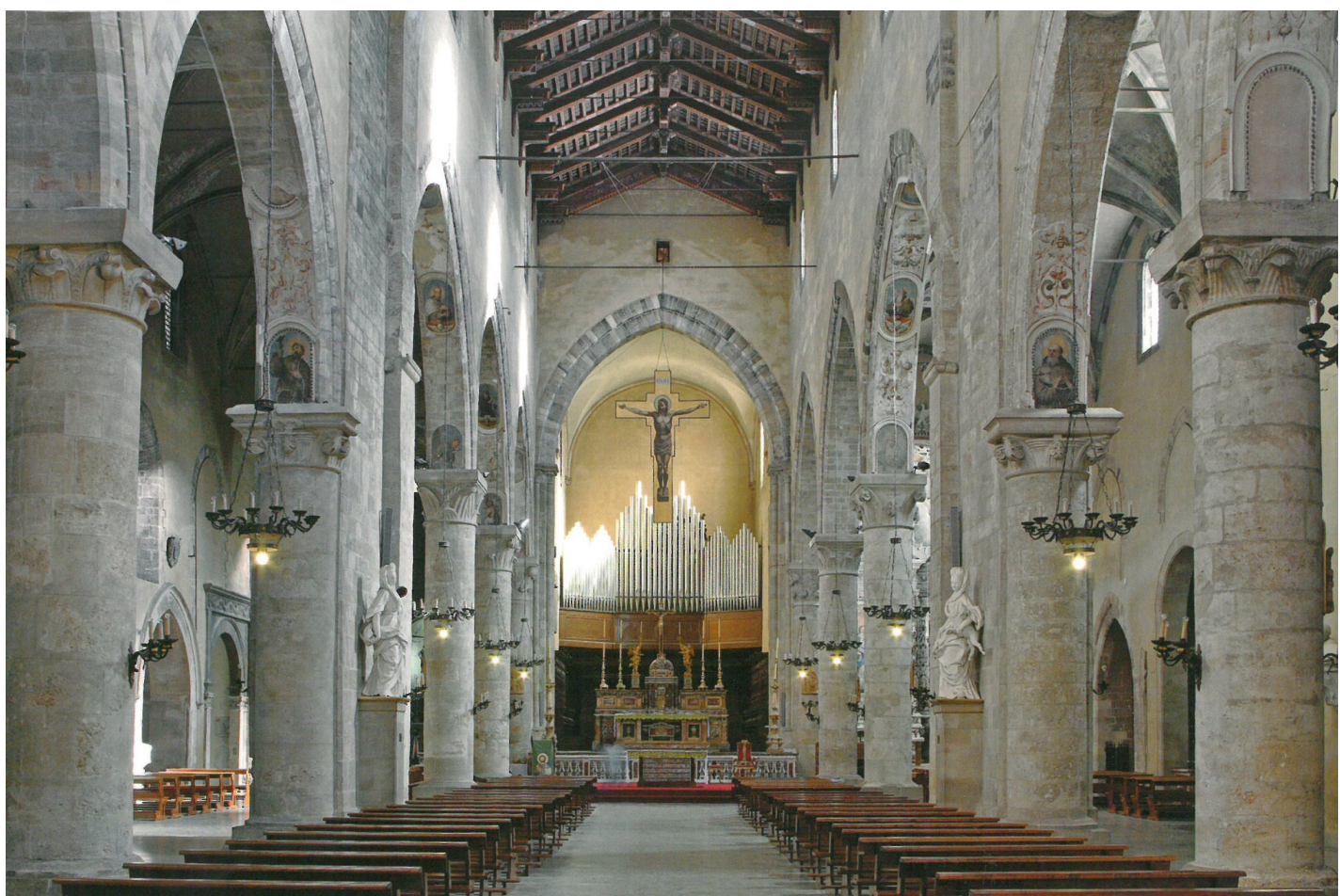

1. Perspectiva interior de la Basílica de San Francesco. Palermo

sucede con los oratorios. En cambio, transmutar es «convertir una cosa en otra», lo que implica el deseo de simulación, máscara, engaño en definitiva de la 'verdad' arquitectónica de camarines y sagrarios. Desde luego que ambos verbos podrían ser empleados sinonímicamente, pero a nuestro juicio su significado último encierra matices decisivos para una hipótesis de trabajo susceptible de desarrollo futuro, que ahora solamente apuntamos.

\section{La Basílica de San Francesco y su reeducación barroca}

La llegada de los hijos de Francisco de Asís a Palermo se sitúa entre 1224-1235, a tenor de las referencias cruzadas entre fuentes literarias y documentales (Rotolo, 2010: 25). De admitirse la primera data, apuntada por el célebre cronista franciscano Lucas Wadding (1732: I, 104), la presencia seráfica en la capital siciliana ${ }^{4}$ habría sido una feliz realidad en vida del mismo Poverello, cuyo fallecimiento acaeció en
1226 solo dos años después de la presunta fundación panormitana. El temprano establecimiento de la Orden en la isla posibilitó su magnífico y estratégico posicionamiento en vertientes capitales del organigrama local, lo que explica su notable arraigo social, la expansión y florecimiento de los establecimientos conventuales y la rápida accesibilidad de sus individuos a las mitras y dignidades eclesiásticas (Enzensberger, 1987: 45-62). Sin embargo, hubo de discurrir tiempo para que los frailes pudiesen materializar el deseo de contar con una iglesia propia en la ciudad, al verse afectada la comunidad por los enfrentamientos entre Federico II y el papa Gregorio IX, artífice por cierto de la canonización de Francisco de Asís el 16 de julio de 1228. Dado que el emperador había ordenado la paralización de las obras del templo ya emprendidas, los franciscanos no pudieron retomar el proyecto hasta la muerte de Federico en 1250. A partir de ese instante, fueron libres de acometer una fábrica «in opere sumptuoso» que se corresponde, en gran medida, con la repristinada basílica actual [1]. Construida en dos fases comprendidas entre 1255-1264 y 1266-1277 (Rotolo, 


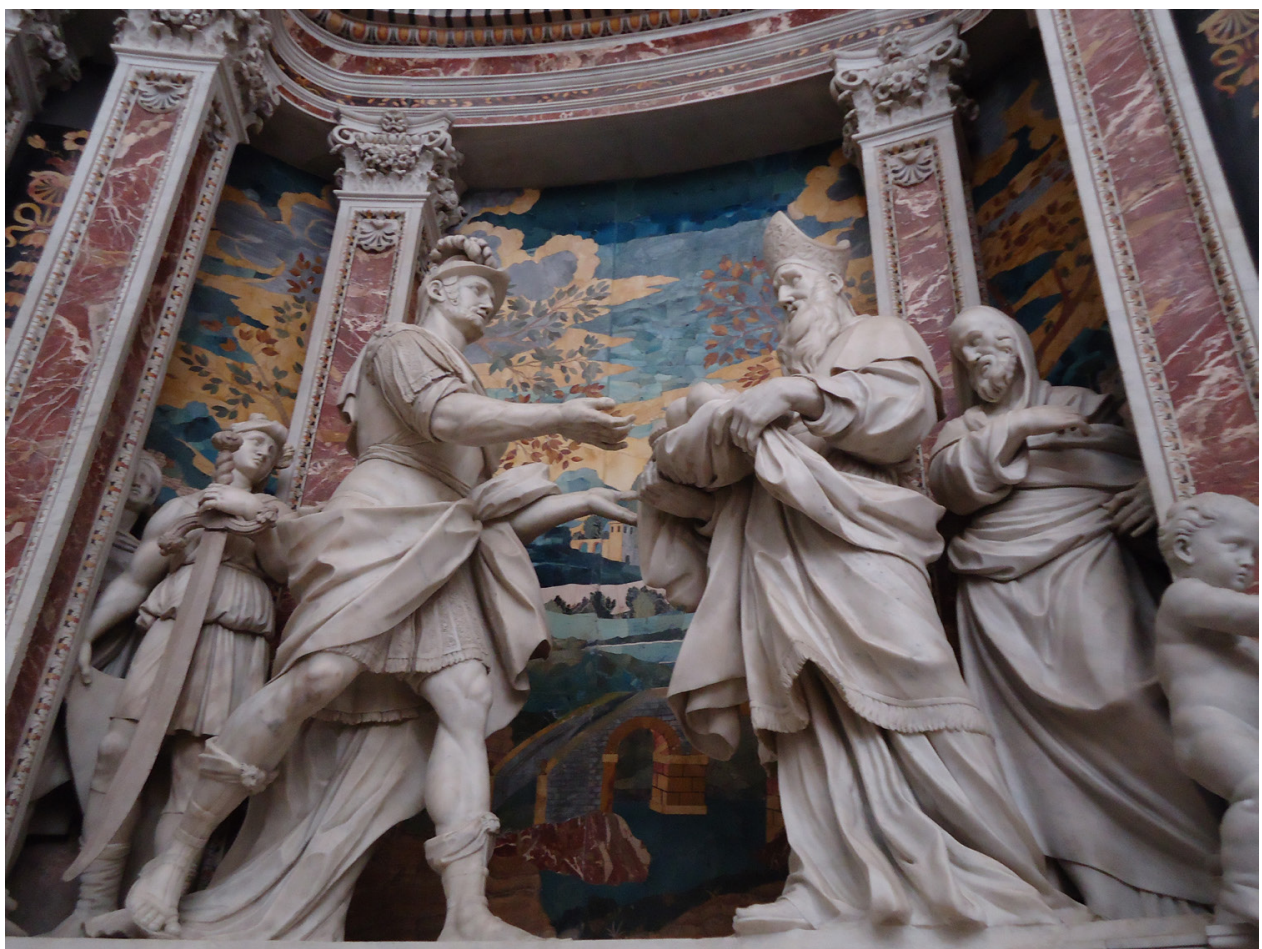

2. Gioacchino Vitagliano y Giacomo Serpotta, Encuentro de David y Ajimelec (c. 1708). Iglesia del Gesú (Casa Profesa). Palermo

2010: 45, 51), su planimetría e impronta siguieron el modelo marcado por la Iglesia del Santo Spirito de Palermo (Rotolo, 1952: 33-57).

La estructura primitiva era la propia de un templo gótico basilical de tres naves, rematadas en otros tantos ábsides poligonales y arquerías apuntadas alzadas sobre robustas columnas, con capiteles vegetales recortados de ascendencia cisterciense. Por motivaciones litúrgicas ya asentadas en la arquitectura religiosa precedente, el santuario quedaba perfectamente diferenciado en términos espaciales y rituales del cuerpo basilical propiamente dicho, merced a la sobreelevación del pavimento y la ubicación de sólidos pilares de sección rectangular remachando las uniones interiores entre ambos recintos por la nave principal. Como era de esperar, la inmediata instauración de los patronatos aristocráticos familiares y particulares dio curso a una frenética actividad de mecenazgo y promoción artística. La dotación de las correspondientes capillas funerarias vino a ser el punto de partida de las sucesivas y radicales transformaciones que depararon consecuencias irreversibles a la impronta edilicia original, por no hablar de las drásticas alteraciones alentadas por los frailes.

Especialmente frustrante para las expectativas de la comunidad fue levantar de cimientos, entre 1589-1591, un nuevo ábside central, de planta rectangular y más profundo (Rotolo, 1967: 153-178) que permitiese trasladar el coro al presbiterio, de manera que la sillería renacentista labrada años antes por Giovanni y Paolo Gili (c.1515-1520) quedara asentada junto al altar. Con este propósito, el 6 de diciembre de 1589 el maestro Giovanni Antonio Vitale se obligaba ante Bartolomeo de Aidone, Guardián del convento de San Francesco, a acometer la demolición y sucesiva reconstrucción del ábside mayor de la iglesia ${ }^{5}$, conforme a la traza de Giuseppe Giacalone, maestro mayor de la fábrica 6 . Pese a que en la escritura de contrato se adoptaban las precauciones oportunas a propósito de la cualificación de los operarios y la solvencia de las obras ${ }^{7}$, lo cierto es que la destrucción del primitivo cerramiento trajo consigo la pérdida de la espectacular iluminación que la orientación ritual del altar hacia Oriente le brindaba al bañarlo intensamente con los rayos 
del sol, con la consecuente experiencia metafísica y cristológica. En este sentido, la incapacidad del nuevo sistema de iluminación (dos ventanas rectangulares y óculo central) para crear la ambientación mistérica deseada fue un completo fracaso (Rotolo, 2010: 120), al no revalidarse en el flamante recinto sacro la atmósfera y el misticismo emanantista que los ventanales góticos propiciaban a la cabecera medieval.

Al perpetrarse tan agresiva intervención en el epicentro hierocrático de la basílica, se cuestionaba definitivamente su integridad arquitectónica. En otras palabras, la veda estaba abierta para la modificación de los dos ábsides menores y su reconversión en las respectivas capillas de San Francisco y la Inmaculada. Sobre esta cuestión, el barroco tendría la última palabra al propiciar la reeducación conclusiva de un templo medieval, ya sensiblemente adulterado en su identidad prístina, y 'convertirlo' al lenguaje estético que hacía furor en toda Europa, diríase de modo significativamente compulsivo en Sicilia y, siendo todavía más precisos, en el contexto especifico de las promociones arquitectónicas de las poderosas órdenes religiosas en Palermo. Sin duda, el revulsivo en este terreno fue el grandioso templo del Gesú, epicentro de la Casa Profesa de la Compañía y referente obsesivo, por no decir frustrante, para las restantes religiones. Levantado de nueva fábrica, los muros interiores del Gesú fueron enteramente cubiertos de una antológica ornamentación marmórea entre 1597-1767 (Lo Jacono, 1939: 113122), convirtiéndose en la punta de diamante de la maniera sontuosa en la capital y en paradigma inexcusable para unas decoraciones imposibles de superar en magnificencia, riqueza material, erudición iconográfica y excelencia plástica.

Tan apabullante demostración de poder no minó los ánimos de los comitentes. Prueba de ello son los revestimientos parietales de las iglesias de Santa Caterina, Immacolata Concezione al Capo, Santa Cita, Santa María di Valverde y Santa María dell'Ammiraglio, sin olvidar la Cappella del SS. Crocifisso en la Catedral de Monreale. Ello no significaba que dominicos, filipenses o teatinos renunciasen a contar en sus iglesias conventuales (San Domenico, Sant'Ignazio Martire all'Olivella y San Giuseppe dei Teatini, respectivamente) con algún que otro testimonio constructivo adscrito a la maniera sontuosa. Tampoco los franciscanos podían ser menos, ni quedarse atrás a la hora de sumarse a la moda. La mejor prueba fue la remodelación integral del ábside de la Epístola, en el empeño de conferir una fisonomía ad hoc a un lugar

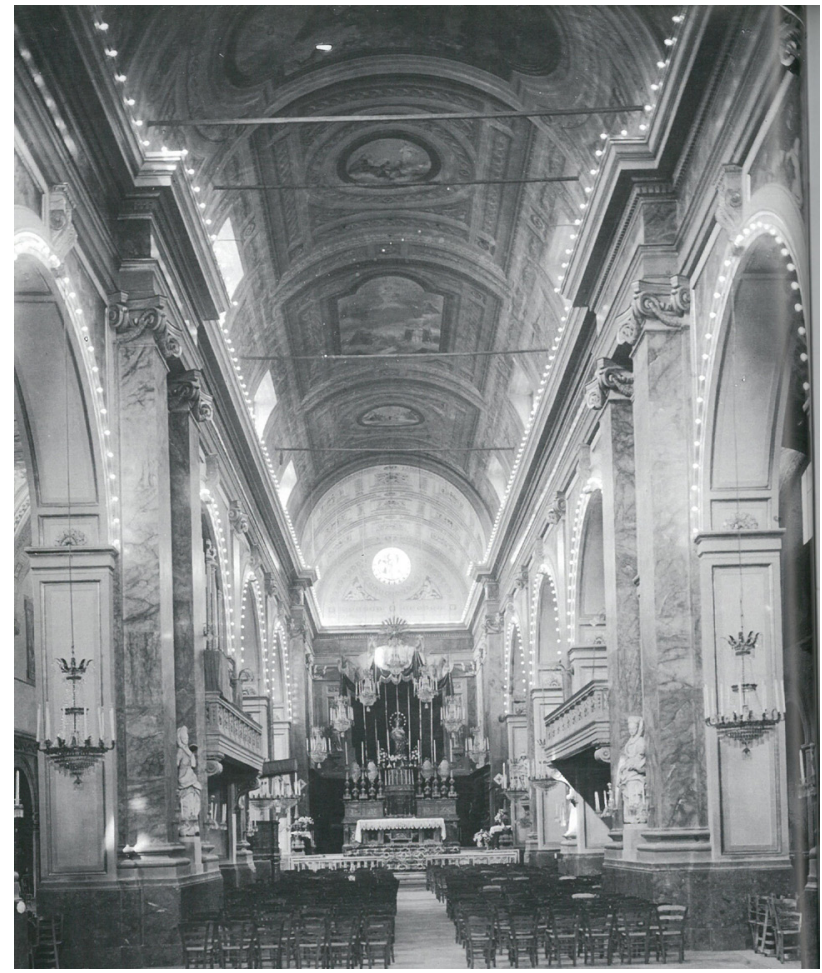

3. Revestimiento neoclásico de la Basílica de San Francesco (Palermo), superpuesto al aparato barroco que mantuvo entre 1723-1823. Entre 1837-1943, la iglesia medieval permaneció nuevamente oculta hasta su repristinación después de la II Guerra Mundial

de culto tan emblemático para ellos como el dedicado a la Inmaculada. Sobre todo, desde que el 16 de noviembre de 1624 la ciudad la declarase patrona de Palermo en señal de gratitud por el cese de la epidemia de peste, profiriendo el voto solemne de celebrar anualmente su festividad en San Francesco. Además de la ejecución de una hermosa estatua de plata de la Inmaculada entre 1646-1647, el Senado panormitano, titular del ius patronatus de la capilla, alentó entre 1649-1726, con el concurso de los frailes, la no menos deslumbrante y profusa ornamentación del recinto a base de mármoles, mosaicos, esculturas y pinturas (Marafon, 2010: 407-409).

En esta tesitura era 'imprescindible' que la basílica se vistiese del barroco, optándose por la maniera apparente. Nadie más capacitado dentro y fuera de la capital para conseguirlo que Giacomo Serpotta, estando todavía reciente su apoteósico triunfo en la renovación del adyacente Oratorio de San Lorenzo, entre 1699-1706. Tal decisión convirtió San 
Francesco en punto de convergencia de sendas maniere. Igual sucedió con la Casa Profesa de la Compañía, cuando la Congregación de la Cruz y Martirio de Cristo determinó promover en sus dependencias altas la construcción de un Oratorio al gusto del momento (la Cappella del Sabato) para los ejercicios espirituales, encargando a partir de 1693 su programa escultórico al joven Procopio Serpotta (Giannino, 2003: 41).

La transfiguración barroca de San Francesco imponía la adopción de criterios distintos a los habituales en este tipo de intervenciones. De entrada, la estructura arquitectónica de la basílica mostraba una complejidad que hacía inviable el camino marcado por los oratorios. El definido perímetro rectangular de estos recintos solía brindar un campo de actuación libre y lleno de posibilidades al disponer de paramentos uniformes dóciles en extremo a los caprichos del estuco, lo cual no sucedía en el maltratado inmueble medieval. La solución fue recurrir a los revestimientos para transformar las columnas en pilares y el conjunto de la nave principal en «una sala-spettacolo», donde entrarían en escena, y nunca mejor dicho, las diez Virtudes Seráficas ${ }^{8}$. La necesidad de renunciar a dos de los tres elementos de su trinomio esencial, indujo a Giacomo Serpotta a optimizar, quizás como nunca en otra ocasión, las aptitudes retóricas y monumentales de la escultura programática. En San Francesco solamente podía contar con ella para construir un relato único, didáctico, edificante, moralizante y secuenciado a lo largo de la nave central, en torno a las diez cualidades que adornan al buen franciscano mediante la contemplación de sus pertinentes personificaciones alegóricas: Modestia y Mansedumbre [4], Humildad y Verdad [5], Victoria y Teología [6], Fortaleza y Fe [8] y, finalmente, Caridad y Castidad [9].

El desafío de Serpotta era conseguirlo jugando con dos factores decisivos en esta clase de estatuas: la escala y el material. Tratándose de un oratorio no había problema, pero era preciso demostrar que la escultura en estuco se sobreponía a los prejuicios y se crecía en dimensiones, prosopopeya escenográfica, capacidad discursiva y grandilocuencia expresiva, igualando a su homóloga en materiales 'nobles' en el marco grandioso de una basílica. Alessandro Algardi había roto una lanza a favor de la cuestión con las dos figuras en estuco de San Juan Evangelista (1628) y Santa María Magdalena (1629), modeladas para la iglesia romana de San Silvestro al Quirinale, toda una declaración de intenciones por parte de quien ya poseía una personalidad artística muy segura de sí. Pero, además, el artista panormitano contaba con acreditada experiencia para hacer funcionar una estatua en tales condiciones, al suministrar a su cuñado Gioacchino Vitagliano los modelos para los grupos estatuarios en mármol de David y Ajimelec [2] y David y Abigail (c. 1708) del Gesú de Palermo, donde los protagonistas recortan sus siluetas desde los «teatros perspectívicos» del ábside ante espectaculares paisajes de intarsia. Tampoco puede obviarse que, hacia 1680, Serpotta había afrontado el difícil reto compositivo y modelaje de una estatua pública de máximo compromiso representativo, al tratarse de un monumento ecuestre y regio desaparecido dedicado a Carlos II, rey de España y de Sicilia, para la ciudad de Mesina (Sorrentino, 1913: 379-387; Pascual, 2012: 165-180). El modellino original en bronce conservado en el Museo Pepoli de Trapani delata las evidentes conexiones de la propuesta de Serpotta con las versiones de Pietro Tacca en su Felipe IV (1634-1640) de la madrileña Plaza de Oriente y Gian Lorenzo Bernini en el Constantino (1654-1668) de la Scala Regia vaticana.

Gracias al investigador franciscano Filippo Rotolo (2010: 356-357) sabemos que la remodelación de la basílica de San Francesco estaba concluida en abril de 1723, estrenando un aspecto que no podía ser más sugerente: "L'aula magna della Chiesa, che per la presenza di queste Virtú poteva essere vista come una passerella di moda, per via del simbolismo iconográfico, acquista invece un messaggio altissimo». Conviene no olvidar que la fórmula de crear un itinerario teológico mediante esculturas monumentales, que desde la entrada del templo conduce al altar hilando un concetto, contaba con un precedente prestigioso, cronológicamente muy próximo al ciclo de Virtudes panormitano. Nos referimos a la galería de los Apóstoles, dispuesta en la nave central de la Basílica de San Juan de Letrán entre 1705-1718, resultante de una nómina de escultores de primer nivel: Camilo Rusconi, Giuseppe Mazzuoli, Pierre Le Gros, Pierre Monnot, Francesco Moratti, Angelo de'Rossi, y Lorenzo Ottoni.

La ausencia de referencias documentales conclusivas a la mentoría, condiciones de obra y pormenores de ejecución de la reeducación barroca de San Francesco impiden establecer conclusiones sólidas, más allá de la apuntada lectura estético-iconográfica global del ciclo de las Virtudes 


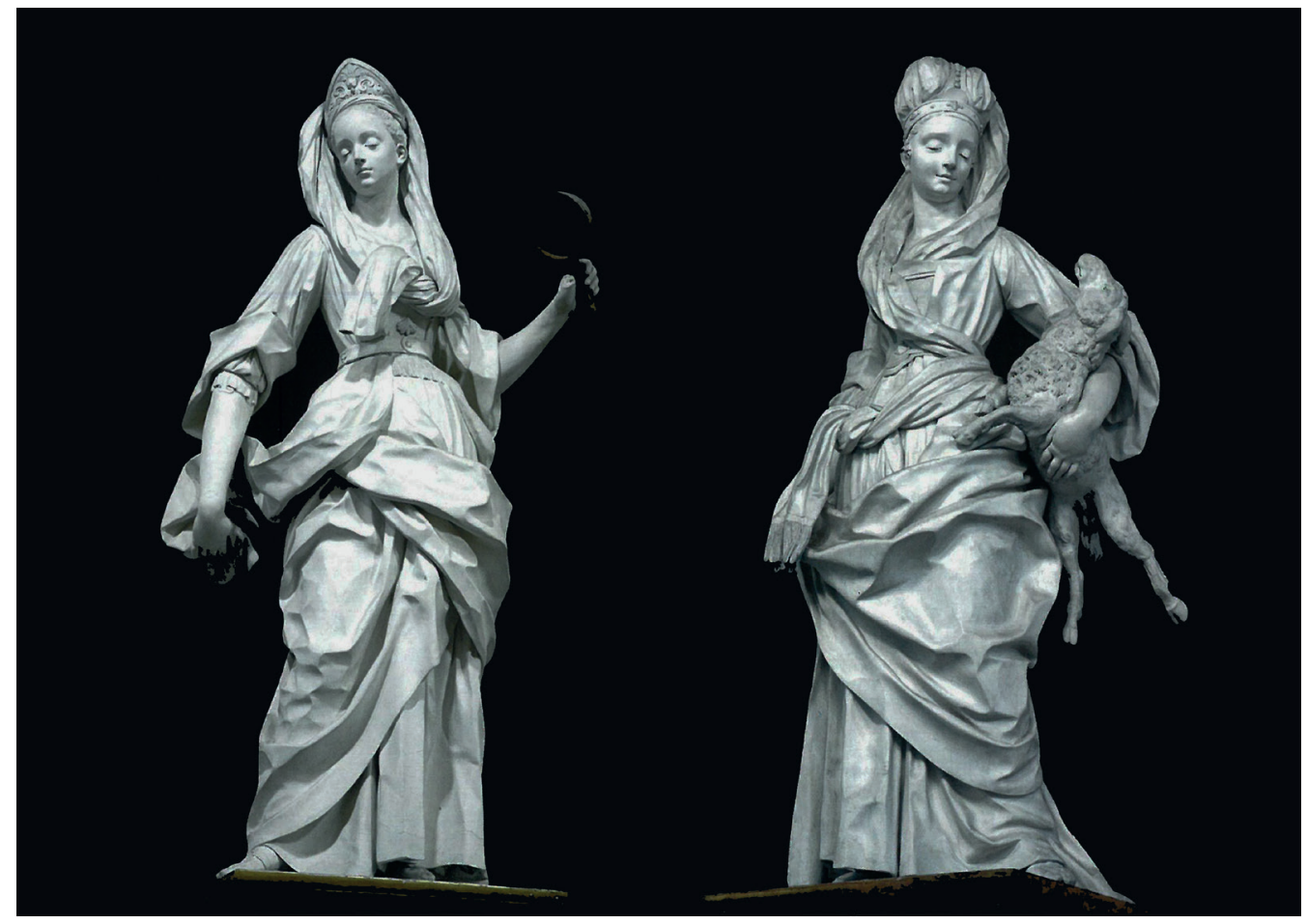

4. Giacomo Serpotta, La Modestia y la Mansedumbre (c. 1723). Basílica de San Francesco. Palermo

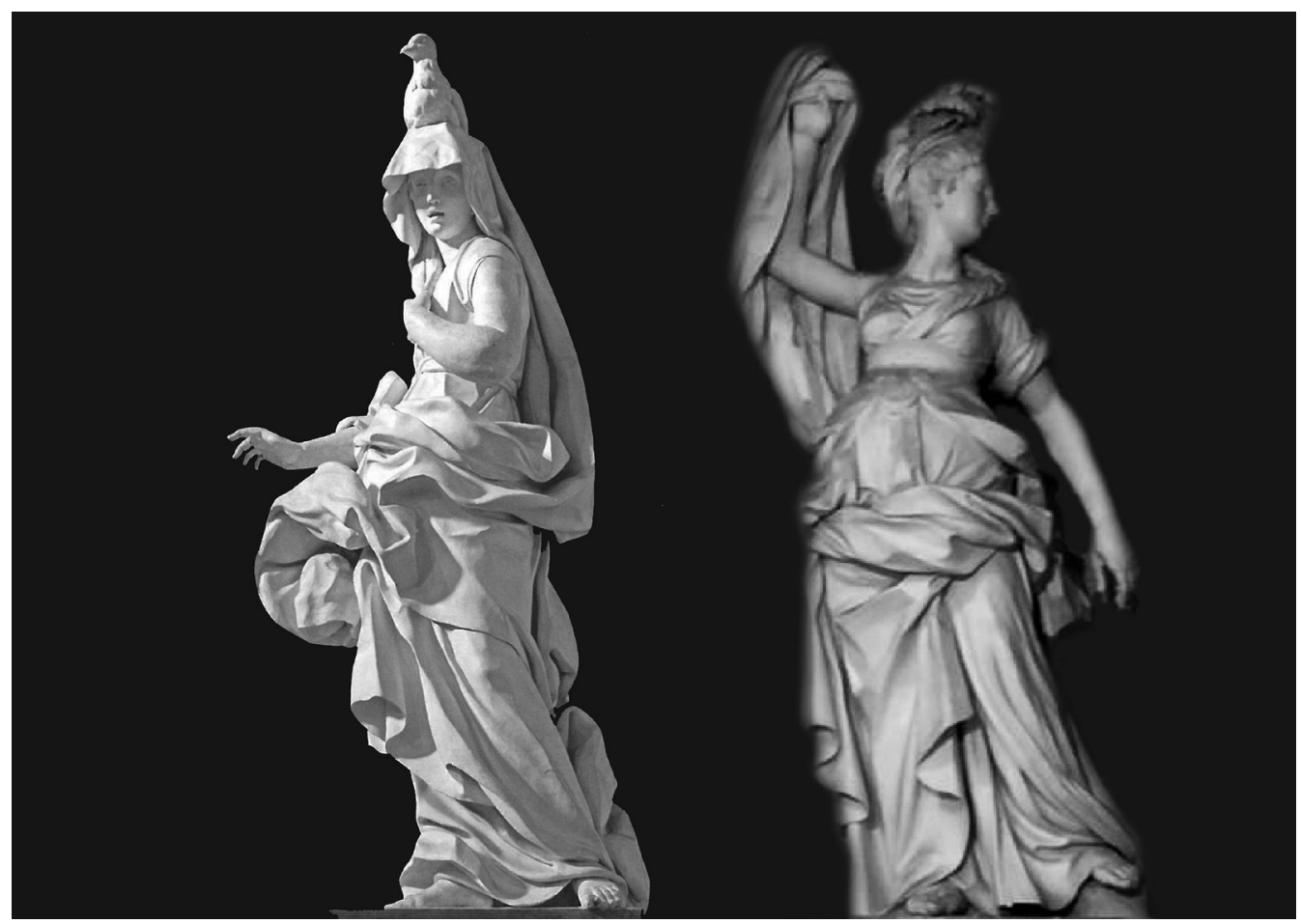

5. Giacomo Serpotta, La Humildad y la Verdad (c. 1723). Basílica de San Francesco. Palermo 
Seráficas y el análisis histórico-artístico singularizado que efectuamos seguidamente. La situación se agrava al constatar que la configuración y disposición primigenias del programa permanecieron intactas por un espacio temporal relativamente corto, el siglo comprendido entre 1723-1823, sin darle apenas tiempo a ser recogidas con exhaustividad en descripciones literarias $u$ otras fuentes. El intenso terremoto que sacudió Palermo ese último año dañó considerablemente la basílica y con ella las estatuas de Serpotta. Desde esa fecha hasta hoy mismo, las Virtudes han sido objeto de distintas intervenciones (Guttilla, 1998: 21-23) y cambios de ubicación aleatorios (y no siempre acertados) que hacen imposible cualquier propuesta de lectura tendente a establecer relaciones iconológicas entre ellas, en función de un emplazamiento concreto. Máxime, cuando la reconstrucción de la basílica tras el seísmo también fue el pretexto para acometer un nuevo revestimiento y transformarla en un edificio neoclásico con un orden de pilastras jónicas, sobrepuestas a los soportes primitivos que quedaron enmascarados bajo los pilares setecentistas de estuco [3]. Con la fisonomía estrenada en 1837, el templo volvía a ser objeto de agresiones por los bombardeos de la aviación americana de 1943, repristinándose arquitectónicamente en los años sucesivos conforme al lenguaje constructivo de sus inicios (Tinaglia, 2005).

\section{Las Virtudes Seráficas. Poética, idea y representación}

Giacomo Serpotta se enfrentó al tema iconográfico de las Virtudes en varias ocasiones ${ }^{9}$. Con una versatilidad y capacidad resolutiva asombrosas demostró ser, en efecto, «il più felice improvvisatore della scultura del Settecento" (Argan, 2002: III, 454). En esta secuencia de variaciones sobre el mismo asunto, ningunas superan en áulica solemnidad, modernidad y prestancia estatuaria a las Virtudes Seráficas de San Francesco. Ya apuntábamos que se trata de figuras destinadas a actuar en solitario, a las cuales se exigía un resultado artístico mucho más acabado y contundente que a sus restantes compañeras, imbuidas por el contrario del aparatoso efectismo coral de los oratorios (Giuffrè, 1996: 34-36). Legítimas sucesoras de aquella capacidad de verbalización intelectual de la lconología de Cesare Ripa, las Virtudes Seráficas aparecen embargadas de glamurosa so- fisticación y, al mismo tiempo, de una funcionalidad retórica propia que cobra fuerza 'parlante' gracias al ejercicio individualizado de gramática corporal y gestual y, por supuesto, a la lectura de los atributos. Desde una perspectiva estética, la plasticidad del modelado construye unos modelos femeninos de sensual verismo, no exento de contenidos tintes eróticos en algunos casos, sabiamente compensados merced a la gracia e introspección de las expresiones y la elegancia de los movimientos y drapeados all'antica vistos bajo la óptica del revisionismo berninesco. En los rostros aflora de nuevo el culto a una belleza lánguida, aristocrática y ausente de los tipos de Alessandro Algardi, y, en última instancia, ese eclecticismo (o mejor «fusionismo») personal tan característico de Serpotta, igualmente evocador de los juegos de diagonales y la volumetría angulosa de los pliegues propia de Camilo Rusconi, sin dejar de remitir a la sugestión romana de Antonio Raggi y Ercole Ferrata, la delicadeza de Francesco Duquesnoy o la repristinación manierística de Filippo Parodi, a quien recuerdan el alargamiento de los cuellos y el decorativismo del detalle.

Decimos «eclecticismo» entendiéndolo no como mezcla indiscriminada y caprichosa de estilos y referencias, sino como un repertorio versátil de soluciones plásticas que van adquiriendo presencia y definición personal en el trabajo escultórico conforme lo exigían las circunstancias iconográficas, morfológicas y estilísticas que informan la temática en cuestión o una particular noción del decoro iconográfico, de trascendente proyección y presencia en su obra. Según señalábamos en su día, ese decoro impide, consecuentemente, clasificar la escultura de Giacomo Serpotta conforme a rígidas codificaciones deudoras de círculos, escuelas o maestros concretos. Todos ellos y ninguno se hacen visibles en la miríada de figuras exentas, relieves y paramentos ornamentales modelados para los oratorios palermitanos, sometiéndose siempre al pulso y los criterios del artista (Sánchez, 2015: 228-229).

La experiencia acumulada en cada trabajo serviría, pues, al artista para asentar las vías procedimentales que configuran las claves de su poética: el conocimiento de la escultura antigua griega, helenística y romana y de las expresiones artísticas locales sicilianas (especialmente, del clasicismo renacentista de Antonello Gagini y su círculo, junto a las obras de los arquitectos Paolo y Giacomo Amato y del pintor Antonino Grano), el influjo de los grandes nombres 


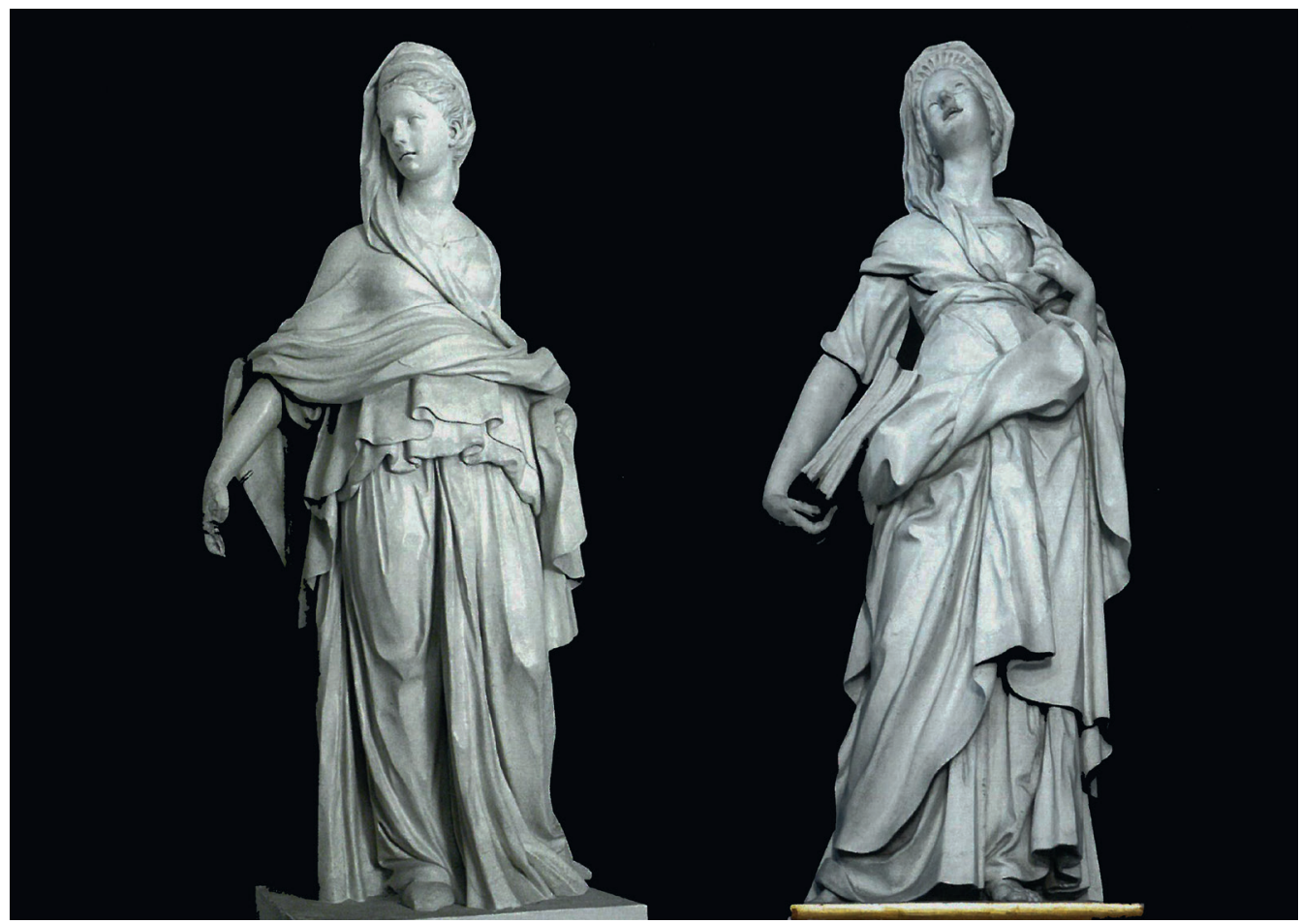

6. Giacomo Serpotta, La Victoria y la Teología (c. 1723). Basílica de San Francesco. Palermo

propios del barroco romano y napolitano (Palazzotto, 2013: 9-13) y el manejo indistinto de multitud de fuentes, modelos y recursos instrumentales varios (Palazzotto, 2009: 3949), perfectamente constatado en el testamento otorgado por Serpotta el 23 de febrero de 1732, a cuatro días de su muerte (Montaperto, 2013: 20, 57-58). Con todo, la cuestión de las influencias del barroco peninsular todavía no es fácil de dilucidar, a pesar de la estancia en Roma en torno a 1685-1688 que los biógrafos del artista consideran clave en su formación.

Como decíamos antes, nunca sabremos a ciencia cierta de qué forma interactuaban entre sí las esculturas serpottianas en la nave de la basílica de San Francesco y desde qué ubicaciones concretas. Por el contrario, sí está clara la idea de extrapolar del conjunto de las Virtudes aquéllas que se consideraban más significativas, idiosincrásicas y consustanciales del espíritu seráfico. A nuestro juicio, una posible exégesis del programa pasaría por el intento de clasificar las Virtudes en tres bloques o ejes conceptuales ternarios presididos por la Caridad, considerada desde el pensamiento franciscano (Cornejo, 1684: 571) «Reyna coronada de las Virtudes, de todas haze más dilatado su imperio». En última instancia, esta tesis remite a la Teología Mística de San Buenaventura (1947: IV, 649-655) al afirmar que la unión de las Virtudes en sus distintas tipologías «se efectúa por la Caridad, por lo cual dice: el centro con amor [...] La Caridad, en cuanto sufrida, es origen de las virtudes activas, y en cuanto amadora de Cristo, lo es de las contemplativas». Así, las cosas, el planteamiento del Doctor Seráfico nos invita a distinguir en el ciclo serpottiano un primer grupo de Virtudes teológicas que engloba la Fe, la Teología y la Verdad; un segundo bloque de Virtudes especulativas, contemplativas o consuetudinales, determinantes de pautas actitudinales en el modus vivendi personal al dictado de la Humildad, la Mansedumbre y la Modestia y, finalmente, un tercer estadio donde se encontrarían las Virtudes cardinales, activas u operativas que imprimen carácter al individuo, cuales la Fortaleza, la Castidad y la Victoria.

Si esto sucede en el plano teórico, otro aspecto importante a discernir aquí es el modus operandi seguido en la 

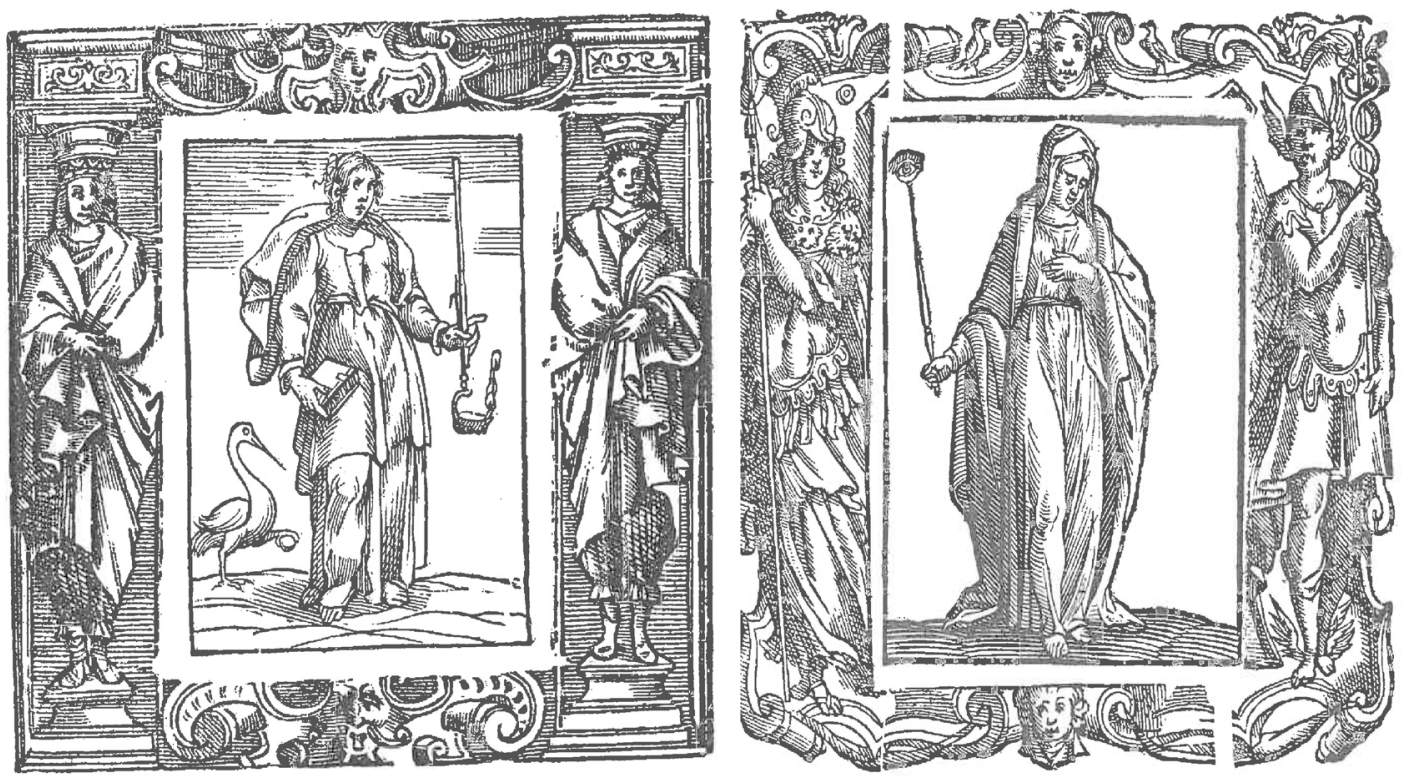

7. Cesare Ripa, Iconología. Alegorías de la Vigilancia y la Modestia. Ilustraciones de la edición de Siena, Herederos de Matteo Fiorimi, 1613. Obsérvense las analogías compositivas con las Virtudes Seráficas de la Teología y la Fe, respectivamente

construcción visual de las Virtudes Seráficas. Aunque inspiradas en Ripa, su composición iconográfica no es convencional, en cuanto a considerarlas siempre transcripciones unívocas, más o menos fieles o literales, de las alegorías respectivas y sus correspondientes equivalencias literarias y gráficas. Más bien al contrario, sí que detectamos un ejercicio de agudeza para intuir y seleccionar de la fuente primaria aquellos aspectos que más interesaba destacar, extractándolos de la lconología y combinándolos inteligentemente para configurar la imagen deseada, sin descartar cierta violencia estructural de lo ya tipificado icónicamente. Procopio Serpotta suscribió respecto a Ripa un criterio idéntico al de su padre, según constatan los estudios que se le vienen dedicando recientemente (Mansueto, 2014: 222-249). En un contexto cultural que demandaba toda suerte de temas alegóricos en iglesias y sepulcros obligando a los artistas a volver repetidas veces sobre los mismos y sobre sus propias soluciones, no puede sorprendernos que la creatividad y la reinterpretación subjetiva fueran cualidades más valiosas que nunca en un artista tan prolífico como Giacomo Serpotta, sometido al reto de reinventarse casi constantemente. Ya sentenciaba Boucher (1999: 22) que «Ripa no lo explicó todo acerca de la alegoría en el Barroco, pero su libro suministró nuevas posibilidades para expresar ideas abstractas mediante formas concretas". En este sentido, la lectura singular de las Virtudes Seráficas que ahora proponemos se basa en un intento de comprender los mecanismos de la figuración visual barroca, reconstruyendo la intención del artista y/o sus mentores a la hora de configurar el sentido retórico y persuasivo preciso que esperaba dárseles, en un viraje desde lo universal a lo particular, de lo genérico a lo especifico, del espíritu mendicante al espíritu seráfico, en suma. La metodología seguida demuestra el estrecho seguimiento de la /conología, cuyas descripciones se acoplan a la perfección, salvo matices, a las pautas compositivas e iconográficas de las Virtudes Seráficas.

La Modestia es una hermosa joven ceñida con un cíngulo de oro "porque ya en las Sagradas Escrituras con dicho cíngulo se simbolizan la Templanza y la Modestia, en uso de la cual se refrenan y reprimen los ambiciosos y lascivos pensamientos y las pasiones desenfrenadas", llevando asimismo «la cabeza inclinada en señal de modestia, como suelen hacerlo las honestas doncellas y los hombres Religiosos» (Ripa, 1987: II, 91). El autor de la Iconología es tajante 


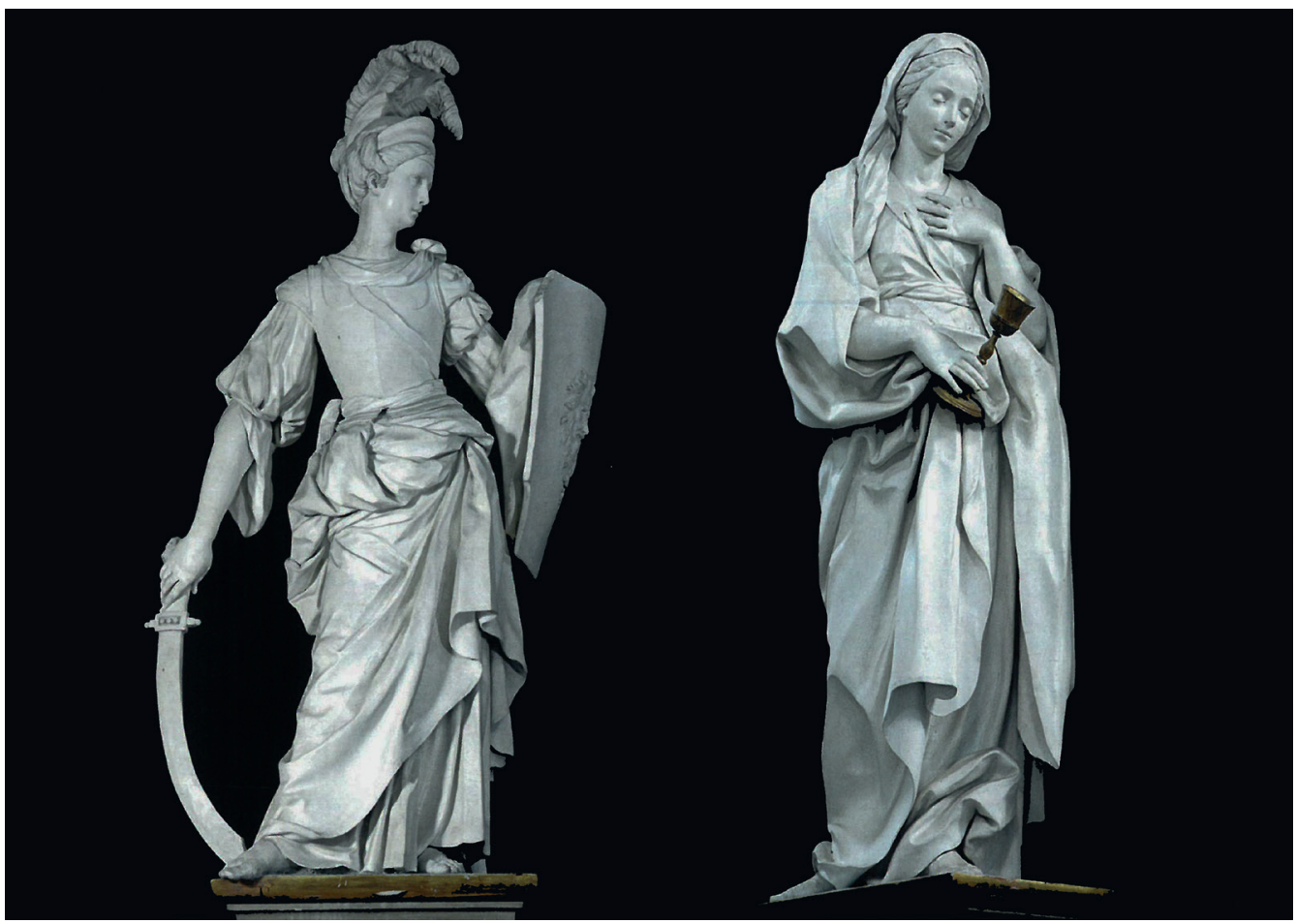

8. Giacomo Serpotta, La Fortaleza y la Fe (c. 1723). Basílica de San Francesco. Palermo

al sentenciar que «la modestia no admite en su compañía cosas superfluas e innecesarias, siendo el tocado ciertamente innecesario y superfluo, así como signo visible de una vana soberbia, sirviéndonos tan sólo de realce y utilizándose para mostrar la elevación y altivez que encierran nuestras mentes». Serpotta parece contradecirlo al coronar la figura con una ostentosa diadema que, en cambio, adquiere una significación pertinente al comprobar el gesto de desdén del personaje hacia el espejo, culpable de alimentar la vanidad de quien no se preocupa en ocultar los dones que se tienen. El deliberado apropiacionismo del espejo (atributo clásico de la Prudencia) y su relectura polisémica y de la diadema brindan al escultor la posibilidad de reinventar la imagen de la Modestia en la cultura visual del momento, una actitud por lo demás persistente en gran parte de las esculturas del ciclo.

La Mansedumbre se muestra en cándido diálogo con un cordero que pugna por saltar de sus brazos, luciendo su cabeza un exótico tocado que remeda la tiara del Sumo Sacerdote de Israel en clave de atrezzo operístico. Su impronta prescinde enteramente del aparato gráfico y textual previsto en la Iconología, verificando en su lugar sendas paráfrasis sobre la significación del animal en las alegorías de la Humildad y la Inocencia. Al igual que la persona mansa, el cordero «no tiene ni fuerza ni intención de perjudicar a ninguno, y además porque, viéndose ofendido, ni se aíra ni se enciende en deseos de lograr venganza; antes, al contrario, tolera pacientemente y sin repugnancia que le arrebaten la lana y aún la vida» (Ripa, 1987: I, 529). De ahí que «el cordero es verdadero símbolo y retrato del hombre humilde y manso, por cuya razón Cristo Nuestro Señor fue llamado Cordero» (Ripa, 1987: I, 499).

La Humildad es la Virtud Seráfica por excelencia y Francisco de Asís su indiscutible paradigma. Salvatore Vitale (1645: 472) refiere que el Poverello renunció al sacerdocio por su causa, al sentirse indigno cuando un ángel le hizo ver una ampolla llena de un refulgente licor, al tiempo de revelarle la necesidad de poseer un alma igualmente pura para administrar el cuerpo y la sangre de Cristo. Por tanto, para conservar el orden perfecto de las Virtudes la persona requiere de la Humildad, por cuanto «no es solamente acto 
de virtud reformadora de la naturaleza, sino que es también ejemplo de virtud reparadora; por donde tiene más de medicamento que de complemento; y porque la enfermedad que corrompe al género humano es principalmente el fasto de la soberbia y de la arrogancia, el medicamento debe efectuarse por su contrario» (Buenaventura, 1947: VI, 33). Giacomo Serpotta hace de la Humildad una de sus más espectaculares alegorías, al tiempo de la más declaradamente berninesca de la serie. El ampuloso drapeado acompasa la rotación helicoidal del cuerpo y la vehemente gestualidad de esta figura femenina «que lleva al pecho la siniestra, manteniendo la diestra abierta y extendida», en inequívoca impetración coloquial con el mensaje lanzado al espectador: «la mano en el pecho muestra que el corazón es el lugar donde reside la Humildad. La diestra abierta es símbolo de que la Humildad debe ser real y paciente» (Ripa, 1987: I, 499). Sobre la cabeza cubierta por un velo, dejando levemente en penumbra el enigmático semblante de la figura, despunta la paloma. Serpotta la toma de la alegoría de la Simplicidad y transfiere esta ave a una virtud afín «por habernos sido dada por Cristo Nuestro Señor como símbolo de la verdadera simplicidad por medio de la cual es posible alcanzar el reino de los cielos» (Ripa, 1987: II, 316).

La Verdad es una mujer altamente sofisticada, «resplandeciente, y de nobilísimo rostro, vestida [...] con gran pompa y adorno» (Ripa, 1987: II, 392). Reconocemos en ella una de esas figuras serpottianas fascinantes, acicaladas con elementos inesperadamente contemporáneos a las fastuosas modas cortesanas, que hace realidad la intención de la cultura manierista y barroca de representar la virtud como una variedad de lo verdadero, hermoso y deseable que suscita el deleite de los sentidos y el intelecto. Con majestuosa arrogancia, el personaje levanta sobre su cabeza un velo que descubre el primoroso peinado y el tocado de plumas, en referencia a la potestad de esta virtud para descubrir lo que está escondido y liberar a la humanidad de las tinieblas del error o del engaño.

Los prototipos estatuarios están tan asumidos en la Victoria que el conjunto destila un neoclasicismo casi pre-canoviano, con esa delicadeza y fragilidad del tipo femenino en connivencia con el preciosismo flagrante en los plisados y efectos rizados de las telas. El artista la imagina «según los antiguos» con el vestido prescrito, «cubriéndose además con una clámide corta» (Ripa, 1987: II, 400) y llevando en la mano la palma (perdida) alusiva a la templanza del religioso «como símbolo del premio que en el Cielo reciben los que dominan sus pasiones, y a sí mismos se rigen y someten. En efecto la palma no se dobla por más que se someta a fuertes pesos, levantándose siempre» (Ripa, 1987: II, 353).

De la alegoría bifronte de la Teología, Serpotta se queda con el rostro que mira al Cielo, «el de edad más juvenil, porque las cosas elevadas y remotas, son las más agradables y atractivas». En la mano derecha sujeta el Evangelio, fuente de la Revelación, apoyando la otra «sobre el pecho mostrando gravedad, pues ésta es ciencia de ciencias». La Iconología indica que la alegoría sujete el borde de la vestidura en dirección al suelo, simbolizando «que una parte o aspecto de la Teología se dirige hacia las cosas bajas». En este punto, se impone otra vez la paráfrasis subjetiva al mantenerse el gesto de asir la tela del manto, pero en sentido inverso y en complicidad con la elevación de los ojos «porque la Teología no reposa en cosa alguna que pueda ser inferior de condición, yendo directamente en persecución del Divino conocimiento, donde halla regla y norma para saber y entender la totalidad de las cosas y su clara ordenación» (Ripa, 1987: II, 358).

En la Fortaleza, Serpota opta por una interpretación más convencional y clásica que rompe con la teatralidad casi decadente de otras versiones suyas. Para la serie de San Francesco, potencia la imagen amazónica de esta virtud bajo la impronta de una mujer armada con coraza y yelmo de plumas. En la espada desnuda que sujeta con la diestra se «significa la fortaleza y el valor corporales», mientras la izquierda porta un escudo con cabeza de león alusiva a «la generosidad de ánimo» (Ripa, 1987: I, 440).

La Fe evoca casi literalmente la representación prescrita para la Fe Católica, como una mujer "que se apoya la diestra sobre el pecho, mientras sostiene un Cáliz con la siniestra mirándolo fijamente». Al igual que la Teología, la Caridad y la Castidad, la escultura de la Fe revela cierta dependencia formal de los grabados de la lconología [7] y [10], reduciéndolos a mera referencia compositiva, en pro de una más aquilatada conceptualización y definición visual de la virtud representada: «La mano que mantiene sobre el pecho muestra cómo en el interior de su corazón la viva y verdadera Fe se contiene, haciéndonos acreedores al premio por el hecho mismo de poseerla [...] Con la otra mano sostiene el Cáliz, símbolo de la Fe, en el que se fundan todas nues- 


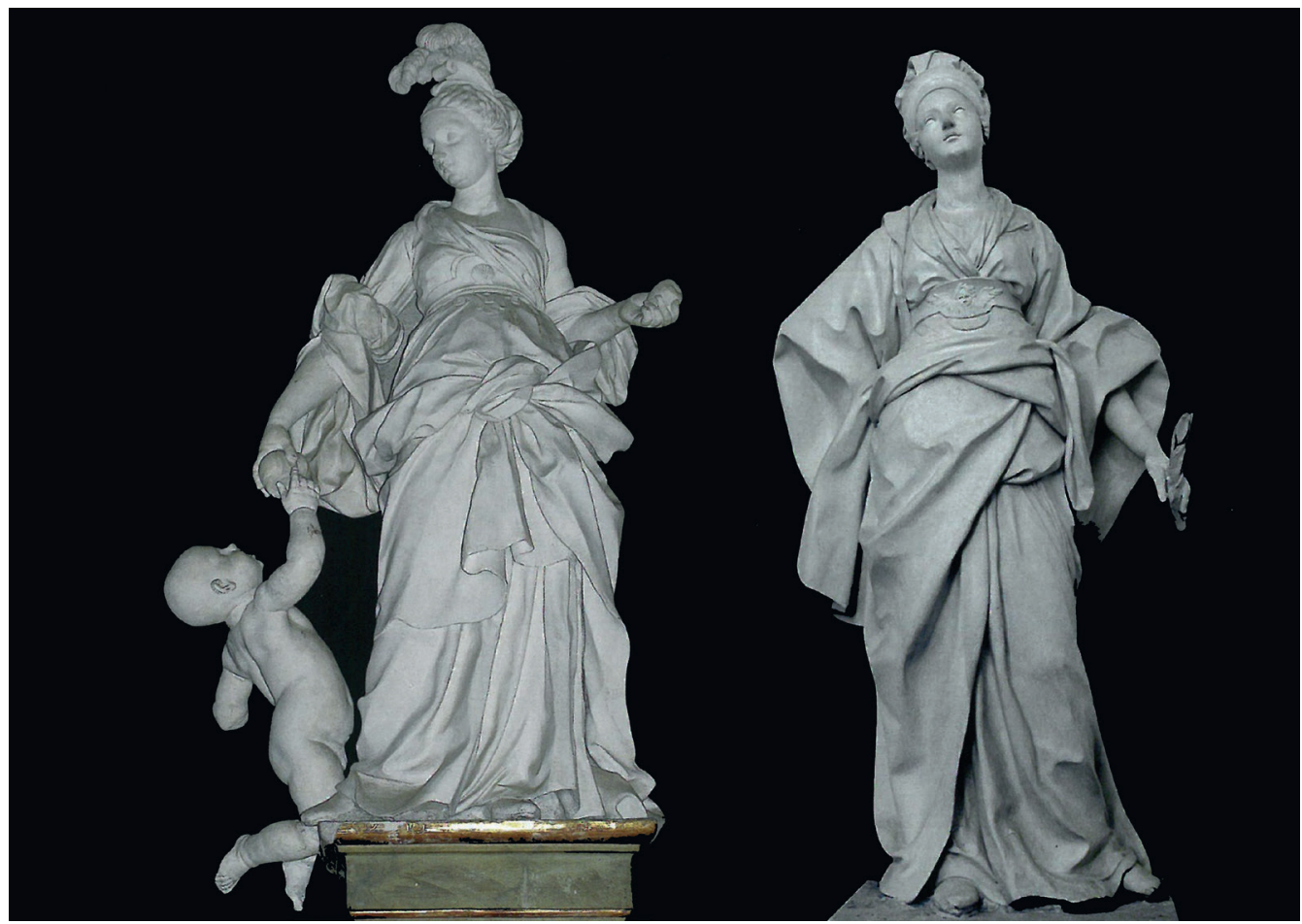

9. Giacomo Serpotta, La Caridad y la Castidad (c. 1723). Basílica de San Francesco. Palermo
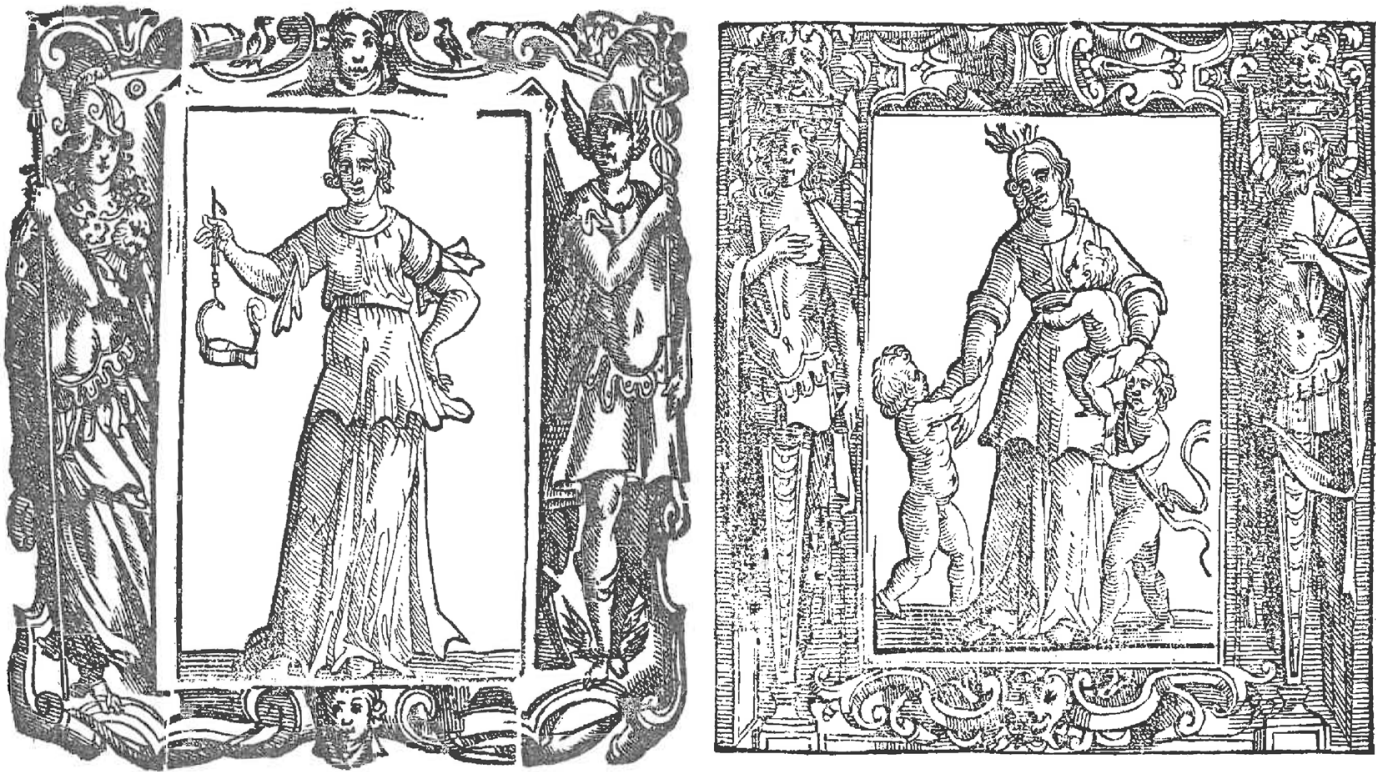

10. Cesare Ripa, Iconología. Alegorías de la Vida y Ánimo y la Caridad. Ilustraciones de la edición de Siena, Herederos de Matteo Fiorimi, 1613. Obsérvense las analogías compositivas con las Virtudes Seráficas de la Castidad y la Caridad, respectivamente 
tras esperanzas y la verdadera finalidad de nuestros deseos» (Ripa, 1987: I, 402-403).

El artista hace de la Caridad el trasunto de una dama de alcurnia que presenta en su mano izquierda el ardiente corazón, «significando así que la caridad es afecto puro y ardiente del ánimo que se orienta hacia Dios y sus criaturas». Con la diestra, entrega el panecillo a un putto netamente serpottiano que desborda el perímetro del pedestal. Además de significar la única concesión 'decorativa' dentro de la serie, la lconología lo justifica a los pies de la alegoría, donde «ha de estar sujetando la mano derecha de la figura» (Ripa, 1987: I, 161-163).

Por último, la Castidad se refleja en una mujer hermosa y de honesto semblante que «irá vestida de largo como una Virgen Vestal, ceñida por la cintura con una faja». La impostación clasicista de la escultura subraya el inflamado misticismo expresivo y la teatralidad con que la mirada se eleva en demanda de una fuerza superior, imprescindible para vencer la tentación del deseo carnal. En su mano izquierda ostenta una rama de laurel «por cuanto dicho árbol tiene grandísima semejanza con la Castidad, ya que esta virtud debe ser perpetua, como perpetuo es el verdor del Laurel. Del mismo modo, debe la castidad gritar y resistirse contra el ataque de las amorosas llamas, tal como crepitan y se resisten las hojas y ramas de Laurel arrojadas al fuego» (Ripa, 1987: I, 181-182).

Descontextualizadas del mundus furiosus en el que nacieron, las Virtudes Seráficas rivalizan hoy con las fotografías de moda de Steven Klein por su premonitorio posmodernismo neobarroco. Sin embargo, fueron creadas con la misión de inculcar a quienes las contemplasen en la Basílica de San Francesco la necesidad de ser sincero, firme, afable, discreto, generoso, humilde, solidario, coherente, idealista y honesto. En este punto, vuelven a sorprendernos y a fascinarnos por cuanto el siglo XXI sigue necesitando que ellas nos lo sigan recordando.

\section{Notas}

1 La coyuntura vino favorecida a raíz de una estancia de investigación de tres meses (desde 01/11/2013 hasta 31/01/2014) como profesor invitado en la Accademia de Belle Arti de Palermo (Università Statale), dentro del Plan Propio de Investigación para Ayudas a Estancias en Centros de Investigación de la Universidad de Málaga.

2 El proyecto investigador Giacomo Serpotta. Escultura, transfiguración arquitectónica, modernidad barroca fue presentado y defendido, el 14/07/2017, por el autor de este trabajo en el concurso-oposición para la obtención de la plaza de Catedrático de Universidad en el Área de Conocimiento afín, adscrita al Departamento de Historia del Arte de la Universidad de Málaga.

3 Así se constata en los manuscritos del canónigo de la Catedral de Palermo, Antonino MONGITORE (1663-1743), conservados en la Biblioteca Comunale di Palermo (B.C.P.): Sacro Teatro Palermitano (Ms. Qq D 11-15), Chiese e Conventi (Ms. Qq E 4), Dell'Ilstoria Sagra di tutte le Chiese, Conventi, Monasterj, Spedali et altri luoghi pii della cittá di Palermo, le Chiese e le Case dei Regolari. Parte Prima (Ms. Qq E 5) y Le Chiese e Case dí Regolari (Ms. Qq E 5-6).

4 «instrumentum memorat Fratres emisse domos octo cum viridario in Urbe Panormi in contrata seu regione illa civitatis».

5 Archivio di Stato di Palermo (A.S.P.), Corporazioni Religiose Soppresse di Palermo, San Francesco d'Assisi, vol. 194, c. 523r. En: <http://www.cosmedweb. org/pdf_schede/PALERMO-SFrancescodAssisi-1589.pdf> (fecha de consulta: 14/07/2018).

6 «in primis sdirrupari lo dammuso vecchio di ditta tribona, ritagliari li suoi colonni di li pedi di dicto dammuso vecchio per insino in terra, voltari lo dammuso di novo con quillo ordini et modello che detto di Giacaluni li avi dato et si darrà a ditto Joanne Antonio con li soi peduzi di intaglio».

7 «e li mastri chi haveranno di fari tutta la supraditta frabica et imbianchiatu siano di quella sufficientia che contentaranno a detto di Jacaluni e a lu dicto mastri Joanni Antonio».

8 Al parecer, Serpotta también ejecutó para San Francesco otras dos estatuas de los Apóstoles Pedro y Pablo.

9 Entre otros espacios sacros, en los Oratorios del Rosario de S. Domenico (1686-1718) y San Lorenzo (1699-1706) y las iglesias de Santo Agostino (17111729) y S. Matteo al Cassaro (1728-1729). También aparecen en Palermo en las iglesias de S. Francesco de Paola o Badia Nuova (1724) y de los SS. Cosma e Damiano (1722), en Alcamo. En la Badia Nuova de Alcamo, Serpotta replicó las alegorías de la Mansedumbre y la Fortaleza de San Francesco, aunque carecen del nivel artístico de estas.

\section{Bibliografía}

ABBATE, Vincenzo (ed.) (2017), Serpotta e il suo tempo, Silvana Editoriale, Cinisello Balsamo, Milán.

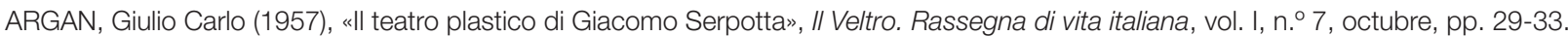
- (2002), Storia dell'Arte italiana, Sansoni-RCS, 3v, Milán. 
BASILE, Ernesto (1911/1981), Le sculture e gli stucchi di Giacomo Serpotta/ pubblicati per cura di Rocco Lentini, con la monografia dell'artista scritta da Ernesto Basile; e prefazione di Corrado Ricci, Società Italiana di Edizioni Artistiche C. Crudo \&C, Torino.

BOUCHER, Bruce (1999), La escultura barroca en Italia, Destino, Barcelona.

BLUNT, Anthony (1968), Sicilian Baroque, Weidenfeld \& Nicolson eds, Londres.

BUENAVENTURA (1947), Obras de San Buenaventura, 6 v, BAC, Madrid.

CORNEJO, Damián (1684), Chronica Seraphica, 2 v., Juan García Infanzón impresor, Madrid.

CHILLÓN RAPOSO, David (2016), Mecenazgo y patrocinio del arzobispo Don Jaime de Palafox y Cardona. Tesis Doctoral, Universidad de Sevilla. En: <https://idus.us.es/xmlui/handle/11441/40620> (fecha de consulta: 24/06/2017).

DI NATALE, Maria Concetta \& Maurizio VITELLA (eds.) (2015), Arredare il sacro in Sicilia. Artisti, opere e committenti dal Medioevo al Contemporaneo, Skira, Ginebra-Milán.

ENZENSBERGER, Horst (1987), «I vescovi francescani in Sicilia (sec. XIII-XV)», Schede medievali, n. ${ }^{\circ}$ 12-13, pp. 45-62.

FAVARA, Giuseppina \& Eliana MAURO (eds.) (2009), Giacomo Serpotta e la sua scuola, Grafill, Palermo.

FERNÁNDEZ, Dominique (1992), La zattera della Gorgone: passeggiate in Sicilia, Sellerio, Palermo.

FODERÀ, Leonardo (ed.) (1996), Giacomo Serpotta: architettura e apparati decorativi settecenteschi a Palermo, Flaccovio, Palermo.

GARSTANG, Donald (1996), "Origin and early development of marbling in Palermo», Antologia delle Belle Arti, n. ${ }^{5}$ 52-55, pp. 80-99.

- (1990), Giacomo Serpotta e gli stuccatori di Palermo 1560-1790, Sellerio, Palermo.

- (2001), «Marmi maschi a Palermo: dalla Nascita del Vernacolo all'abside di Casa Professa», en María Concetta Di Natale (ed.), Splendore

di Sicilia. Arti decorative dal rinascimento al Barocco, Charta, Milán, pp. 152-169.

- (2006), Giacomo Serpotta e i serpottiani: Stuccatori a Palermo 1656-1790, Flaccovio, Palermo.

- (2008), Giacomo Serpotta, Flaccovio, Palermo.

GIANNINO, Alfonso (2003), La Chiesa del Gesú' a Casa Professa. Palermo, Officine Tipographiche Aiello \& Provenzano, Palermo.

GIUFFRÈ, Maria (1996), «Architettura e decorazioni negli oratori serpottiani», en Leonardo Foderà (ed.), Giacomo Serpotta: architettura e apparati decorativi settecenteschi a Palermo, Flaccovio, Palermo, pp. 26-37.

GONZÁLEZ TORRES, J., La capilla sacramental en el Barroco andaluz: espacio, simbolismo e iconografía (siglos XVI-XVIII). Tesis Doctoral, Universidad de Málaga. En: <https://riuma.uma.es/xmlui/handle/10630/12832> (fecha de consulta: 24/06/2017).

GUTTILLA, Mariny (1998), «Serpotta a S. Francesco d'Assisi: vicende conservative e restauri», Salvare Palermo, n. ${ }^{\circ} 11$, pp. $21-23$.

HERRERA GARCÍA, Francisco Javier (2012), «De mármoles mixtos coloreados. El proyecto de retablo mayor para la Capilla Real de Sevilla (1683-1694) y su debate internacional», Anuario del Departamento de Historia y Teoría del Arte, n. 24, pp. 49-68.

HILLS, Helen (1996), "Centri e periferie: decorazioni ecclesiastiche in marmi intarsiati nella Palermo del XVII secolo», Arte Cristiana, vol. 84, n. ${ }^{\circ} 11-12$, pp. 405-419.

LETO, Filippo (2005), Giacomo Isidoro Niccolò Serpotta «Magister Stuccator, Scultor e Architettor». L'arte dello stucco a Palermo, La Palermo Ritrovata, Palermo.

LO JACONO, Giorgio (1939), «I marmi mischi siciliani nella Chiesa di Casa Professa a Palermo», Palladio. Rivista bimestrale di storia dell'architettura, n. ${ }^{\circ}$ 3, pp. 113-122.

MANSUETO, Luca (2014), «Procopio Serpotta e la tecnica dello stucco: un episodio sconosciuto a Monreale, iconografia, attribuzione», Annali on line dell'Università di Ferrara. Sezione lettere, vol. IX, n. ${ }^{\circ}$ 2, pp. 222-249. En: <http://annali.unife.it/lettere/article/viewFile/1081/882> (fecha de consulta: 07/07/2018).

MíNGUEZ CORNELLES, Víctor; Pablo GONZÁLEZ TORNEL, Juan CHIVA BELTRÁN e Inmaculada RODRÍGUEZ MOYA (2014), La fiesta barroca. Los reinos de Nápoles y Sicilia (1535-1713), Universitat Jaume I, Castellón.

MARAFON PECORARO, Massimiliano (2010), «Barocco e Controriforma nella Sicilia del XVII secolo. La ricca decorazione marmorea nelle chiese di Palermo durante il dominio spagnolo», en Germán Ramallo Asensio (ed.), La Catedral guía mental y espiritual de la Europa Barroca Católica, Universidad de Murcia, Murcia, pp. 395-438.

MONTAPERTO, Maria Luisa (2013), Oratorio di San Lorenzo, Amici dei Musei Siciliani, Palermo.

MORALES MARTíNEZ, Alfredo José (2010), La piel de la arquitectura: yeserías sevillanas de los siglos XVII y XVIII, Diputación Provincial, Sevilla. 
PALAZZOTTO, Pierfrancesco (2004), Palermo. Guida agli oratori. Confraternite, compagnie e congregazioni dal XVI al XIX secolo, Kalós, Palermo.

- (2009), «Fonti, modelli e codici compositivi nell'opera di Giacomo Serpotta», en Giuseppina Favara \& Eliana Mauro (eds.), Giacomo Serpotta e la sua scuola, Grafill, Palermo, pp. 39-49.

- (2013), «Giacomo Serpotta (1652-1732)», en Giuseppe Bucaro (ed.), Il Serpotta di scena, Centro San Mamiliano, Palermo, pp. 9-13.

- (2015), «Tradizione e rinnovamento nei primi apparati decorativi barocchi in stucco di Giacomo Serpotta a Palermo (1678-1700)», en Maria Concetta Di Natale \& Maurizio Vitella (eds.), Arredare il sacro in Sicilia. Artisti, opere e committenti dal Medioevo al Contemporaneo, Skira, Ginebra-Milán, pp. 81-108.

- (2016), Giacomo Serpotta. Gli oratori di Palermo. Guida storico-artistica, Kalós, Palermo.

PASCUAL CHENEL, Álvaro (2012), «Algunas consideraciones acerca de los bronces ecuestres italianos de Carlos II: vicisitudes, relaciones, usos y funciones», Archivo español de Arte, vol. LXXXV, n. ${ }^{\circ}$ 338, pp. 165-180.

PIAZZA, Stefano (2007), I colori del Barocco: architettura e decorazione in marmi policromi nella Sicilia del Seicento, Flaccovio, Palermo.

PRAZ, Mario (1975), Il Giardino dei sensi: Studi sul Manierismo e il Barocco, Mondadori, Milano.

RECIO MIR, Álvaro (2001), "Génesis del ornato barroco sevillano: causas y significación», en Actas del III Congreso del Barroco Americano. Territorio, Arte, Espacio y Sociedad, Universidad Pablo de Olavide, Sevilla, pp. 791-807.

RIPA, Cesare (1593/1987), Iconología, Akal, 2 v, Madrid.

ROTOLO, Filippo (1952), La Basilica di S. Francesco d'Assisi in Palermo, Scuola tip. Salesiana, Palermo.

- (1967), "Abside centrale della basilica di S. Francesco d'Assisi in Palermo. Documenti e regesto. Vicende storiche», in Archivio storico siciliano, vol. III, n. ${ }^{\circ} 16$, pp. 153-178.

- (2010), La Basilica di S. Francesco d'Assisi e le sue cappelle. Un monumento unico de la Palermo medievale, Palermo: Provincia di Sicilia dei Fratri Minori Conventuali.

SÁNCHEZ LÓPEZ, Juan Antonio (2015), «Escultura, mensaje y ornamento en la arquitectura barroca de Andalucía y Sicilia. Reflexiones a propósito de Giacomo Serpotta y su obra en Palermo», en María del Amor Rodríguez Miranda (ed.), Nuevas perspectivas sobre el Barroco Andaluz. Arte, tradición, ornato y símbolo, Asociación para la investigación de la Historia del Arte y el Patrimonio Cultural «Hurtado Izquierdo», Córdoba, pp. 212-247.

SCARLINI, Luca (2017), Bianco tenebra. Giacomo Serpotta, le giorno e la notte, Sellerio, Palermo.

SESSA, Ettore (2003), «Le chiese della capitale vicereale tra Barocco e tardo barocco», en Ettore Sessa (ed.), Le chiese a Palermo, Ugo La Rosa, Palermo, pp. 35-54.

- (2009), "Giacomo Serpotta e il "pareggiamento delle arti": la decorazione degli oratori fra manipolazione vitalistica e vocazione clasicista», en Giuseppina Favara \& Eliana Mauro (eds.), Giacomo Serpotta e la sua scuola, Grafill, Palermo, pp. 51-72.

SORRENTINO, Antonio (1913), «Un bozzetto di Giacomo Serpotta nel museo di Trapani», Bolletino D’arte, vol. VII, n. ${ }^{\circ} 10$, ottobre, pp. $379-387$. TINAGLIA, Vivi (ed.) (2005), La Basilica di S. Francesco d'Assisi a Palermo. Storia delle trasformazioni e dei restauri, Salvare Palermo Fondazione, Palermo.

VITALE, Salvatore (1645), Historia Seráfica della vita e miracoli del Serafico Padre S. Francesco, Milano, nella Stamperia di Giovanni Pietro Cardi. WADDING, Lucas (1625-1654/1731-1745), Annales Minorum seu trium ordinum a S. Francisco institutorum, Typis Rochi Bernabò, 19 v, Roma. WITTKOWER, Rudolf (1958/1985), Arte y arquitectura en Italia 1600-1750, Cátedra, Madrid. 